\title{
Understanding the Ecology of Blue Elderberry to Inform Landscape Restoration in Semiarid River Corridors
}

\author{
Mehrey G. Vaghti · Marcel Holyoak · Amy Williams • \\ Theresa S. Talley • Alexander K. Fremier • \\ Steven E. Greco
}

Received: 29 January 2007/Revised: 25 October 2008/Published online: 25 November 2008

(C) Springer Science+Business Media, LLC 2008

\begin{abstract}
Societal constraints often limit full process restoration in large river systems, making local rehabilitation activities valuable for regeneration of riparian vegetation. A target of much mitigation and restoration is the federally threatened Valley elderberry longhorn beetle and its sole host plant, blue elderberry, in upper riparian floodplain environments. However, blue elderberry ecology is not well understood and restoration attempts typically have low success rates. We determined broadscale habitat characteristics of elderberry in altered systems and examined associated plant species composition in remnant habitat. We quantified vegetation community composition in 139 remnant riparian forest patches along the Sacramento River and elderberry stem diameters along this and four adjacent rivers. The greatest proportion of plots containing elderberry was located on higher and older floodplain surfaces and in riparian woodlands dominated by black walnut. Blue elderberry saplings and shrubs with stems $<5.0 \mathrm{~cm}$ in diameter were rare, suggesting a lack of recruitment. A complex suite of vegetation was associated with blue elderberry, including several invasive species which are potentially outcompeting seedlings for light, water, or other resources. Such lack of recruitment places increased importance on horticultural restoration for the survival of an imperiled species. These findings further indicate a need to ascertain whether intervention is necessary to maintain functional and diverse riparian
\end{abstract}

M. G. Vaghti ( $₫)$ · A. Williams · A. K. Fremier · S. E. Greco Department of Environmental Design, University of California, Davis, One Shields Avenue, Davis, CA 95616, USA

e-mail: mgvaghti@earthlink.net

M. Holyoak · T. S. Talley

Department of Environmental Science and Policy, University of California, Davis, One Shields Avenue, Davis, CA 95616, USA woodlands, and a need to monitor vegetative species composition over time, especially in relation to flow regulation.

Keywords Blue elderberry · Floodplain restoration . Landscape variables · Sacramento River .

Sambucus mexicana . Valley elderberry longhorn beetle

\section{Introduction}

Ecological restoration aims to reestablish natural communities and the processes that maintain them (e.g., Hughes and others 2001; Sprenger and others 2002). Restoring large-scale processes, such as fire and floods, to the extent that they occurred historically is typically unfeasible in contemporary landscapes. Process restoration on large river floodplains, in particular, is constrained by flow regulation, channelization, and floodplain development (Dynesius and Nilsson 1994; NRC 2002). Local rehabilitation measures offer a potential substitute in the face of these constraints. Restoration of habitat for key species plays a dominant role in biological conservation efforts aiming to curb the increased risk of extinction. Such efforts require understanding the specific local habitat characteristics within a landscape context.

Blue elderberry (Sambucus mexicana C. Presl: Caprifoliaceae) is an important component of riparian ecosystems and is frequently the target of restoration efforts in California's Central Valley because it is the sole host plant of the federally threatened Valley elderberry longhorn beetle (VELB; Desmocerus californicus dimorphus Fisher; Coleoptera: Cerambycidae), which is endemic to the Central Valley (Federal Register 1980, 1994; Linsley and Chemsak 1972; Barr 1991). In addition, blue elderberry provides 
nesting habitat for birds and supports a wide variety of insect and spider species, as well as berries, leaves, and flowers, as food resources for numerous species during the dry summer months. Blue elderberry also supports pollinators and other beneficial insects that provide valuable services to agriculture in neighboring areas (e.g., Allen-Wardell and others 1998; Neal 1998). Despite being the objective for many restoration projects, its basic ecology is not yet well understood and restoration attempts typically have low success rates (Holyoak and Koch-Munz 2008). Improving our basic knowledge of blue elderberry distributions over the floodplain will improve our ability to restore and maintain riparian habitat for a variety of species, thus accelerating site recovery and reducing costs.

\section{Blue Elderberry}

Blue elderberry is a spreading drought-deciduous shrub typically $<8 \mathrm{~m}$ in height. It is assumed that seeds are birddispersed, often distributed as scattered individuals, and adapted to germination in full sun. Seedling growth and survival have been shown to respond positively to nitrogen availability and negatively to saturated soil conditions (Chirman 1994). Hubbell (1997) found blue elderberry seedling survival and growth to be severely reduced by alfalfa competition due to limited light and water. Additionally, blue elderberry seedlings exhibited strong resprouting under stress but suffered significant mortality due to herbivory.

Blue elderberry occurs in the understory of cottonwood and mixed riparian forests, and as elderberry savanna (Vaghti and Greco 2007). Talley (2005) found elderberry frequencies to be significantly correlated with relative elevation; the highest frequencies occurred on intermediate floodplains. Further, older shrubs were associated with increased relative elevation and decreased canopy cover at some scales, and patch dynamics controls varied over the four rivers investigated (three flow-regulated and one unregulated) (Talley 2005). On a regulated river, Williams (2006) found elderberry presence and canopy cover to be most strongly correlated to relative elevation in probability modeling, with floodplain age a secondary variable and distance to river channel a poor predictor. Alternatively, Fremier and Talley (2008) found blue elderberry shrub size positively correlated with lateral distance from the channel on an unregulated river, with small stems more likely closer to the channel.

Connecting patterns of blue elderberry abundance on the landscape to the driving factors first requires understanding the configuration, size structure, and associations with other plant communities. As in many temperate river systems, the processes that created and maintained dynamic riparian habitats historically are absent from the modern landscape due to flow regulation and floodplain constriction (Bay Institute 1998; Greco and Plant 2003). Understanding potential impacts to blue elderberry will aid in restoration site selection and design. In this paper we focus specifically on the Sacramento River, with a large and detailed data set, and use data from other adjacent rivers in the Sacramento Valley to address two goals: (i) to determine the landscape-scale habitat characteristics of blue elderberry and (ii) to examine plant species composition of blue elderberry habitat in remnant forests.

\section{Methods}

Study Sites

Sites were selected in the Sacramento Valley where VELB is endemic and restoration of blue elderberry is frequent (Fig. 1). The region has a semiarid climate, with 34 months of wet, mild weather followed by a hot, dry season. There are 20 major dams in the 7 million-ha watershed that impound winter and spring high flows for flood protection and storage for summer consumption and dryland irrigation. As is typical with flow regulation in the region, winter and spring flows are truncated and summer base flows elevated. The Sacramento River, the American River, Cache Creek, and Putah Creek are dammed; the Cosumnes River is the only river in our study without regulated flow.

The river sections in this study are predominantly single-thread streams with the floodplains comprised of finegrained alluvium. Parts of these rivers still actively migrate, but most sections are impacted by near-bank channel constraints (e.g., riprap) and levees.

Vegetation communities were surveyed over a range of floodplain heights and ages within publicly accessible areas along $125 \mathrm{~km}$ of the Sacramento River. These floodplain vegetation communities are the most extensive and diverse stands remaining in California (Hunter and others 1999). Supplemental stem data were surveyed on $2 \mathrm{~km}$ of the Sacramento River, $12 \mathrm{~km}$ of the lower American River parkway, $3 \mathrm{~km}$ of the Cosumnes River, $13 \mathrm{~km}$ of Putah Creek, and $2 \mathrm{~km}$ of Cache Creek (Fig. 1).

\section{Vegetation and Environmental Correlations}

Using a suite of spatial data sets, forest vegetation was stratified by minimum floodplain age (FPA) and relative elevation (RE) (Table 1). These landscape variables are surrogates for patch age and floodplain hydrology and have been shown to correlate well with the successional model of vegetation change over time (Gillison and Brewer 1985; 
Fig. 1 Sacramento River watershed and Cosumnes River showing the hydrography, vegetation communities study area, and blue elderberry stem diameter study areas

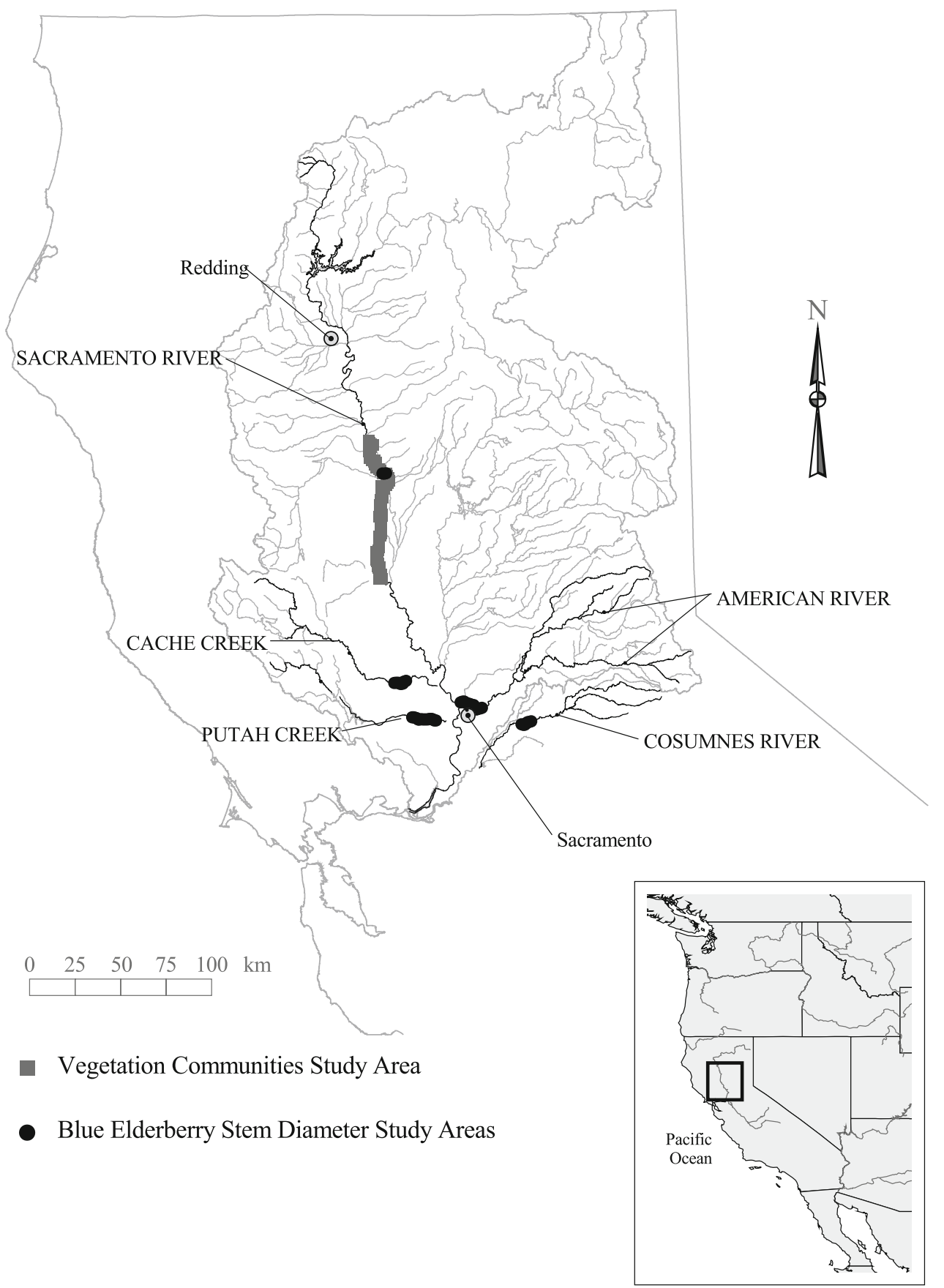

Greco and others 2007). FPA represents the time since floodplain deposition and was calculated using historical data of channel position. Historic maps and aerial photos were subsequently overlaid in a geographic information system (GIS) to identify the time of floodplain deposition by either continuous migration or avulsion events (Greco and others 2007). RE is a floodplain topographic surface relative to a series of modeled long-term low-flow water surface elevations (Greco and others 2008). The modeled water surface elevations used a 45-year low-flow average and were calculated to $\pm 0.3 \mathrm{~m}$ using HEC-RAS (Version 3.0; BOSS International). An interpolated GIS surface was calculated from the modeled water surface elevations and then spatially subtracted from a conventional topographic GIS surface (based on a single datum at mean sea level) of floodplain elevation (Greco and others 2008). RE represents the correlative variable with the influence of hydrology, both surface and ground, with higher values correlating with drier, less frequently inundated floodplains. 
Table 1 Minimum floodplain age and relative elevation source data and resulting classes used in sampling and analysis of vegetation and environmental correlations

\begin{tabular}{cll}
\hline & Source data & Study class \\
\hline Floodplain age & & $1870(>127$ years $)$ \\
Historic maps & 1870 & $1871-1896(101-127$ years $)$ \\
& 1896 & $1897-1904$ (94-101 years) \\
& 1904 & $1905-1937^{\mathrm{a}}(60-93$ years $)$ \\
Photography & $1937^{\mathrm{a}}$ & $1939-1952(46-59$ years $)$ \\
& 1952 & $1953-1966^{\mathrm{a}}(32-45$ years $)$ \\
& $1966^{\mathrm{a}}$ & $1967-1976(22-31$ years $)$ \\
& 1976 & $1977-1987$ (11-21 years) \\
& 1987 & $1988-1997(1-10$ years $)$ \\
& 1997 & 1997 (river channel) \\
Relative elevation & 1997 U.S. Army & $0-2 \mathrm{~m}$ \\
& Corps of & $2-4 \mathrm{~m}$ \\
& Engineers & $4-6 \mathrm{~m}$ \\
& & $6-8 \mathrm{~m}$
\end{tabular}

${ }^{a}$ For river miles 202-219, aerial photography from 1937 and 1966 was replaced with 1938 and 1962, respectively, due to availability

Forested vegetation was classed into broad categories based on canopy cover, height, and color signature using aerial photography from 1997 (Greco and others 2003). Plots were located in polygons $>0.25$ ha classified as "valley riparian," "mixed riparian," and "valley oak" on public lands and point bars. Vegetation patches were located in the field using a GPS (accuracy of $\pm 10 \mathrm{~m}$ ).

During July-September 2002 and 2003 we sampled 200$\mathrm{m}^{2}$ square or rectangular plots for low $(<0.5 \mathrm{~m})$ and medium $(0.5-5 \mathrm{~m})$ vegetation, and $800 \mathrm{~m}^{2}$ for high $(>5 \mathrm{~m})$ vegetation (CNPS 2000). We placed plots at least $10 \mathrm{~m}$ from polygon boundaries. In 2002, we collected species composition and cover data using a randomly placed transect (Vaghti 2003); we used a 0.6-cm-diameter rod to record herbaceous and low shrub vegetation and a densitometer for high shrub and tree vegetation. In 2003 we employed the relevé method of deliberate plot placement and ocular estimation (Williams 2006). We recorded total cover of each species by height class (low, medium, high), as described above. We identified all vegetation to the species level; botanical nomenclature followed Hickman (1993).

\section{Blue Elderberry Stem Size}

Between 2002 and 2004, we conducted an independent investigation of blue elderberry stem diameter along five rivers in the Central Valley. We recorded the location and maximum stem diameter for every blue elderberry shrub growing within 2-20 km stretches of riparian habitat. River reaches selected for investigation were accessible for large stretches and contained "typical" riparian vegetation for most of their area (cleared or paved stretches were avoided). We recorded blue elderberry stem locations using a GPS and measured stem diameters at ground level using calipers.

\section{Data Analysis}

\section{Vegetation and Environmental Correlations}

The two vegetation community studies were combined and analyses executed on blue elderberry presence/absence in relation to the selected environmental variables. To determine patterns of blue elderberry occurrence relative to vegetation types, dominant overstory was defined as the canopy species contributing the most cover to each plot. Environmental characteristics were tested for correlations with blue elderberry occurrence: canopy dominant, floodplain age class, relative elevation class, and river mile. Data groups with fewer than three members were excluded and analyses completed using JMP Statistical Software (Version 4.0.4; SAS Institute Inc.). Plant species percentage cover was arc-sin square root-cover-transformed to satisfy assumptions of normality.

To test for correlations between FPA and RE, these variables were analyzed with Pearson's correlation. Partial correlations were used to determine correlations between blue elderberry presence and each of RE and FPA.

\section{Blue Elderberry Stem Size}

We analyzed blue elderberry stem size data within the five river corridors according to class divisions representing the necessary stem size $(>2.5 \mathrm{~cm})$ for VELB habitat (USFWS 1999). Differences among the five rivers in the frequency of the smallest of stems $(0-2.5$ and $2.5-5 \mathrm{~cm}$ in diameter) were determined using $G$-tests. The 0 - to 2.5 - and 2.5 - to 5 $\mathrm{cm}$-diameter size classes were combined $(0-$ to $5-\mathrm{cm}$ diameter) because of the small number of stems in the 0 - to $2.5-\mathrm{cm}$ class ( $\leq 26$ stems per river).

\section{Results}

Vegetation and Environmental Correlations

Blue elderberry was present in $36.7 \%$ of 139 plots collected. Elderberry cover ranged from $0.2 \%$ to $22 \%$ (mean, $5.6 \% \pm 0.045 \%$ ); associated mean FPA and RE were $78 \pm 33$ years and $4.7 \pm 1.2 \mathrm{~m}$, respectively.

FPA $\left(R^{2}=0.158, \chi^{2}=25.34, p<0.005 ; n=138\right)$ and $\operatorname{RE}\left(R^{2}=0.113, \chi^{2}=18.70, p<0.005 ; n=138\right)$ were significant predictors of blue elderberry presence. The 
greatest proportion of plots containing elderberry was located on higher and older floodplain surfaces (Figs. 2 and $3)$. Floodplain age and relative elevation were highly correlated $(R=0.466, p<0.005 ; n=138)$ but exhibited an independent positive influence of similar magnitude on blue elderberry occurrence. Partial correlations ( $r$ ') for blue elderberry presence/absence and FPA (with effects of RE removed) equaled $0.189(t=2.43, p<0.05 ; n=138)$, and RE (with effects of FPA removed) equaled 0.205 $(t=2.24, p<0.05 ; n=138)$.

There was a significant correlation between the blue elderberry distribution and the dominant canopy species.
Blue elderberry distribution was significantly positively correlated with black walnut (Fig. 4). Of the 30 plots with black walnut canopies, $80 \%$ had blue elderberry, with a mean cover of $6.4 \%( \pm 6.2 \%)$. Additionally, blue elderberry presence was $2 \times$ and $3 \times$ greater in black walnut than in valley oak and cottonwood canopies, respectively (Fig. 4).

Blue elderberry presence showed an increasing downriver trend; however, it was not statistically significant. The distribution of elderberry shrub structure was not significantly related to any of the environmental variables tested.
Fig. 2 Observed proportions of blue elderberry across nine floodplain age (FPA) classes on the middle Sacramento River. The filling of Shasta Reservoir commenced in 1943, corresponding to a FPA of 56 years. Sample sizes are given in parentheses. Error bars are 95\% confidence intervals from a binomial distribution. FPA class 128 (>127 years) had fewer than three members and was excluded

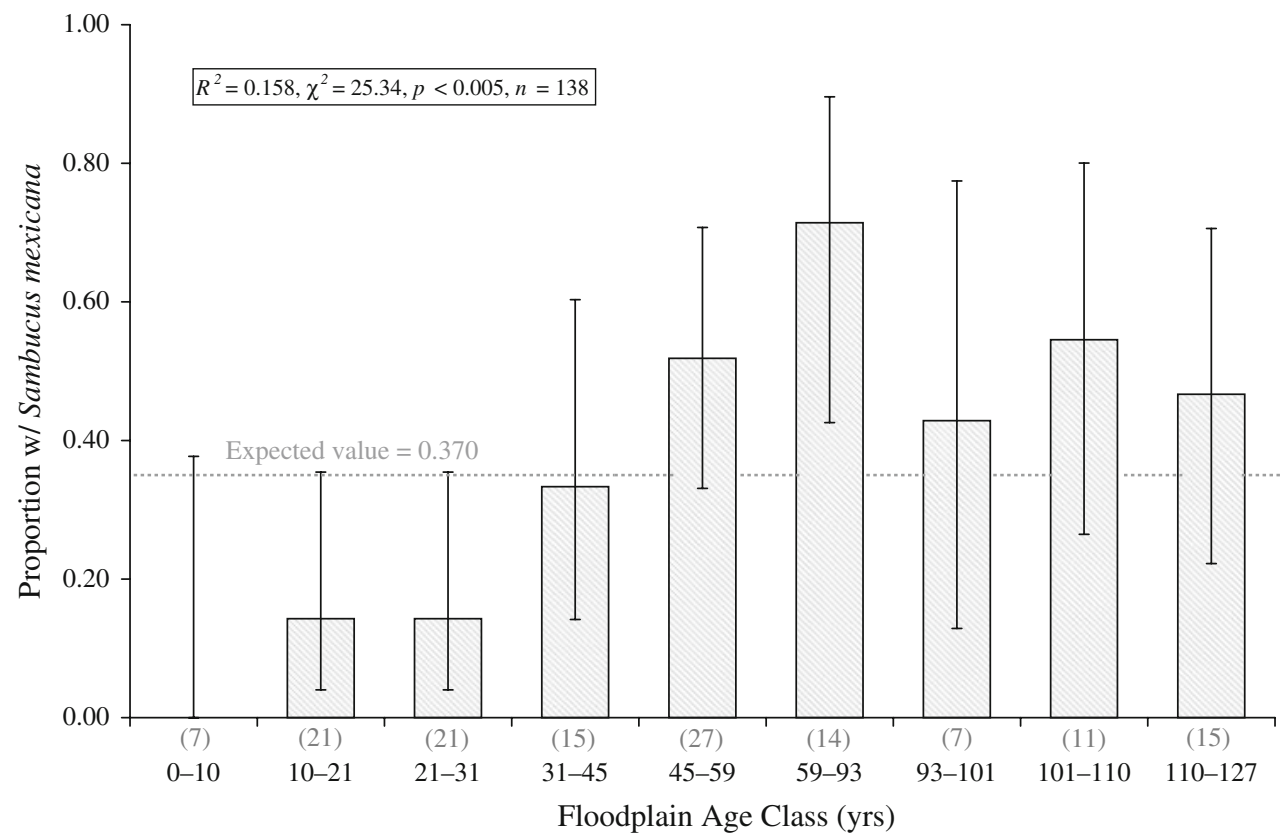

Fig. 3 Observed proportions of blue elderberry across four relative elevation classes on the middle Sacramento River. Sample sizes are given in parentheses. Error bars are 95\% confidence intervals from a binomial distribution. Blue elderberry is more likely to be found on ground $>4 \mathrm{~m}$ above the river's summer low-flow surface

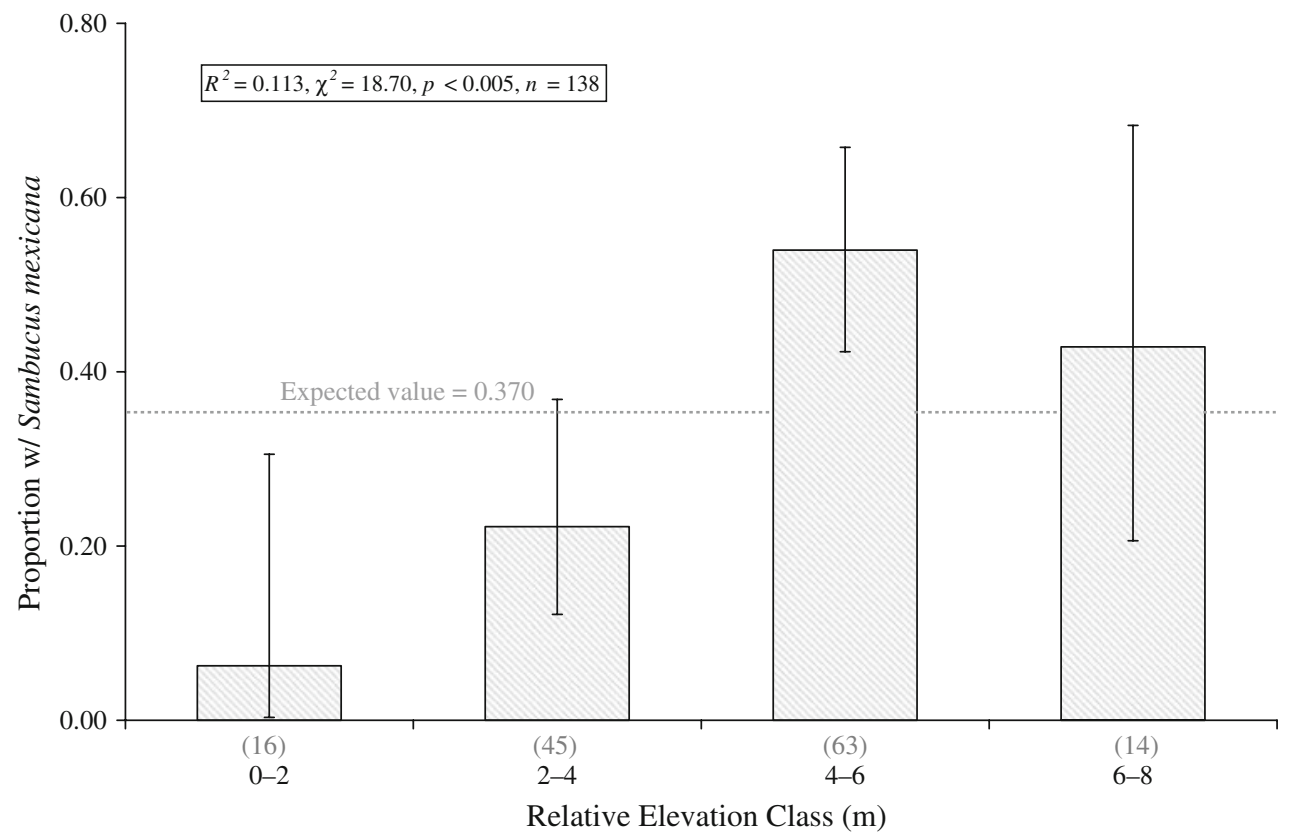


Fig. 4 Blue elderberry distribution varied significantly across six canopy dominants in remnant forests of the Sacramento River. Sample sizes are given in parentheses. Error bars are $95 \%$ confidence intervals from a binomial distribution. Canopy dominants with fewer than three members were excluded

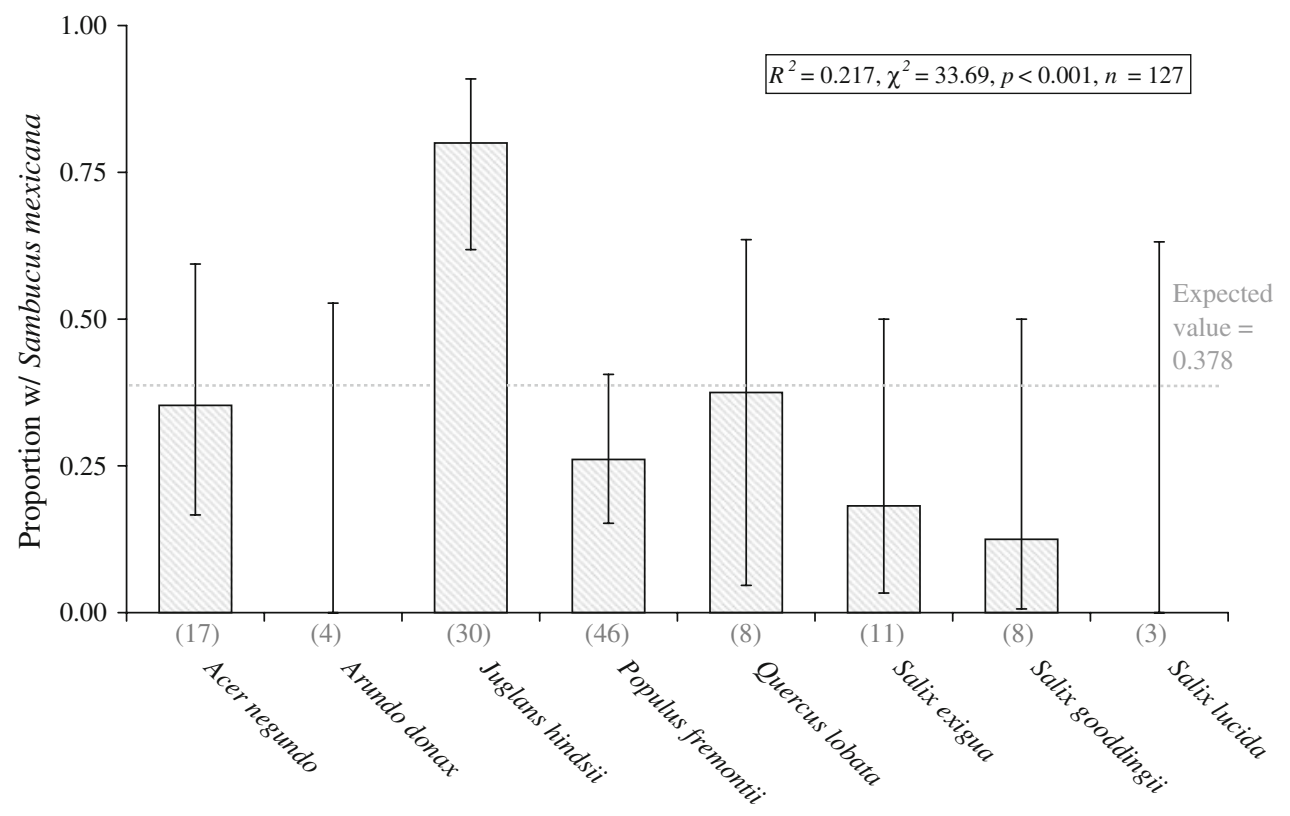

Dominant Canopy Species
A complex suite of vegetation was associated with blue elderberry, as detailed in Table 2. The frequencies of all species together differed significantly in plots where elderberry was present versus absent $(G=186.4$; df $=38$; $p<0.001$ ). Black walnut had the highest frequency and average cover of all species; additionally, box elder and Fremont cottonwood were strongly associated trees. However, these three tree species were also the most frequent where elderberry was absent. Several species of shrubs, herbs, monocots, and vines exhibited high constancy, though mean cover was highly variable. Introduced species of concern included fig (Ficus carica), Himalayan blackberry (Rubus discolor), and giant reed (Arundo donax).

\section{Blue Elderberry Stem Size}

The proportion of stems $<5 \mathrm{~cm}$ in diameter varied significantly across the five rivers investigated $(\mathrm{G}=39.42$, $p<0.001$, df $=3 ; n=153$ to 1079 shrubs per river) (Table 3). The frequency distribution of all recorded stem diameters for each river showed that the four dammed rivers had a lower proportion of small $(<5-\mathrm{cm}$ diameter $)$ stems than the undammed Cosumnes River (Fig. 5 and Table 3). However, there was considerable variation among the dammed rivers. For example, the Sacramento River contained only $5 \%$ of stems that were $<5 \mathrm{~cm}$ in diameter, but for Cache Creek and the American River this figure was $19 \%$ (all of these proportions were significantly lower than the $21 \%$ for the Cosumnes River; Table 3).

\section{Discussion}

Results from vegetation community and stem size studies suggest a lack of blue elderberry recruitment on the Sacramento River. Only 5\% of blue elderberry plants recorded in the vegetation studies were $<0.5 \mathrm{~m}$ tall. Of 153 measured stems, none were $<2.5 \mathrm{~cm}$ and only $5 \%$ were $<5.0 \mathrm{~cm}$ in diameter. Given blue elderberry's intolerance of competition for light and water (Hubbell 1997) and nitrogen (Chirman 1994), it might be expected that the three seedlings recorded would be found in open habitats. These plots showed no obvious trends in canopy cover or species composition; however, tree cover was $>75 \%$ for two plots and $\pm 40 \%$ for the third. Herbaceous cover (including lianas) was $>60 \%$ for all three plots. As seeds are abundant and exhibit strong germination (Hubbell 1997), it would be informative to determine the role of herbivory in natural recruitment of blue elderberry. Additionally, Vaghti (2003) observed Bermuda grass (Cynodon dactylon) to be one of the most pervasive introduced species throughout the study area, occupying openings created by disturbance both high on the floodplain and close to the river in frequently flooded areas. Such species may be outcompeting blue elderberry seedlings for essential resources as documented for alfalfa by Hubbell (1997).

Blue elderberry was strongly associated with black walnut; it is unknown whether this is due to similar ecological requirements or some synergistic effect. Jones (1997), Fremier (2003), and Vaghti (2003) all documented extensive recruitment and establishment of black walnut into a wide range of Sacramento River floodplain habitats. 
Table 2 Frequency and cover of plant species in vegetation community plots where blue elderberry was present versus absent on the middle Sacramento River
${ }^{a}$ Nonnative species

b $J$. hindsii is considered invasive

\begin{tabular}{|c|c|c|c|c|c|c|}
\hline & \multicolumn{3}{|c|}{$\begin{array}{l}\text { Sambucus mexicana present } \\
(n=51)\end{array}$} & \multicolumn{3}{|c|}{$\begin{array}{l}\text { Sambucus mexicana absent } \\
(n=88)\end{array}$} \\
\hline & \multirow[t]{2}{*}{ Frequency } & \multicolumn{2}{|c|}{ Cover $(\%)$} & \multirow[t]{2}{*}{ Frequency } & \multicolumn{2}{|c|}{ Cover $(\%)$} \\
\hline & & Mean & Max & & Mean & $\operatorname{Max}$ \\
\hline Trees & 36.5 & 7.5 & & 32.8 & 6.1 & \\
\hline Acer negundo & 78 & 16 & 58 & 73 & 15 & 97 \\
\hline Ficus $_{\text {carica }}{ }^{\mathrm{a}}$ & 18 & 2 & 46 & 26 & 2 & 58 \\
\hline Fraxinus latifolia & 25 & 2 & 37 & 11 & 1 & 34 \\
\hline Juglans hindsii ${ }^{\mathrm{b}}$ & 90 & 30 & 92 & 63 & 8 & 85 \\
\hline Juglans regia ${ }^{\mathrm{a}}$ & 12 & 0.4 & 17 & 7 & 0.04 & 1 \\
\hline Plantanus racemosa & 16 & 3 & 62 & 13 & 1 & 22 \\
\hline Populus fremontii & 65 & 17 & 91 & 63 & 23 & 95 \\
\hline Prunus sp. ${ }^{\mathrm{a}}$ & 12 & 0.1 & 1 & 1 & 0.1 & 4 \\
\hline Quercus lobata & 27 & 3 & 64 & 30 & 4 & 55 \\
\hline Salix gooddingii & 22 & 2 & 31 & 41 & 7 & 81 \\
\hline Shrubs & 19.3 & 2.3 & & 20.4 & 4.1 & \\
\hline Baccharis salicifolia & 8 & 0.2 & 4 & 6 & 0.5 & 41 \\
\hline Rosa californica & 14 & 0.4 & 12 & 5 & 0.1 & 3 \\
\hline Rubus discolor ${ }^{\mathrm{a}}$ & 41 & 4 & 55 & 32 & 4 & 85 \\
\hline Rubus ursinus & 43 & 5 & 76 & 42 & 11 & 92 \\
\hline Salix exigua & 22 & 5 & 58 & 42 & 11 & 100 \\
\hline Salix lasiolepis & 8 & 2 & 74 & 16 & 2 & 44 \\
\hline Herbs & 23.1 & 3.0 & & 22.6 & 2.5 & \\
\hline Anthriscus caucalis ${ }^{\mathrm{a}}$ & 73 & 12 & 75 & 30 & 3 & 45 \\
\hline Artemesia douglasiana & 14 & 0.1 & 1 & 58 & 9 & 84 \\
\hline Brassica nigra $^{\mathrm{a}}$ & 18 & 0.4 & 9 & 28 & 2 & 79 \\
\hline Centaurea solstitialis $^{\mathrm{a}}$ & 6 & 1 & 33 & 7 & 0.3 & 20 \\
\hline Conyza canadensis & 14 & 0.3 & 10 & 19 & 0.4 & 16 \\
\hline Galium apparine & 71 & 16 & 52 & 48 & 9 & 76 \\
\hline Lactuca serriola $^{\mathrm{a}}$ & 14 & 0.04 & 1 & 13 & 0.2 & 12 \\
\hline Phytolaca Americana ${ }^{\mathrm{a}}$ & 10 & 0.1 & 2 & 13 & 0.4 & 10 \\
\hline Urtica dioita & 14 & 0.3 & 4 & 10 & 1 & 46 \\
\hline Monocots & 36.4 & 4.6 & & 21.1 & 2.2 & \\
\hline Arundo donax ${ }^{\mathrm{a}}$ & 61 & 10 & 75 & 21 & 5 & 99 \\
\hline Bromus diandrus $^{\mathrm{a}}$ & 71 & 15 & 76 & 22 & 3 & 65 \\
\hline Bromus hordeaceus $^{\mathrm{a}}$ & 10 & 1 & 16 & 10 & 0.2 & 6 \\
\hline Carex barbarae & 51 & 8 & 77 & 25 & 2 & 34 \\
\hline Cynodon dactylon $^{\mathrm{a}}$ & 16 & 2 & 52 & 30 & 4 & 62 \\
\hline Elymus glaucus & 67 & 3 & 23 & 32 & 1 & 15 \\
\hline Lolium multiflorum $^{\mathrm{a}}$ & 8 & 1 & 19 & 13 & 3 & 63 \\
\hline Piptatherum miliaceum ${ }^{\mathrm{a}}$ & 37 & 2 & 22 & 26 & 1 & 18 \\
\hline Sorghum bicolor ${ }^{\mathrm{a}}$ & 8 & 0.1 & 4 & 11 & 0.4 & 10 \\
\hline Vines & 46.7 & 3.9 & & 27.0 & 3.6 & \\
\hline Aristolochia californica & 59 & 2 & 12 & 22 & 1 & 41 \\
\hline Clematis ligusticifolia & 43 & 1 & 10 & 17 & 0.3 & 10 \\
\hline Marah fabaceus & 14 & 0.2 & 4 & 6 & 0.1 & 2 \\
\hline Toxicodendron diversilobum & 55 & 4 & 74 & 32 & 2 & 21 \\
\hline Vitis californica & 63 & 12 & 60 & 58 & 15 & 95 \\
\hline
\end{tabular}


Table 3 Total number of blue elderberry shrubs and proportion of main stems $<5 \mathrm{~cm}$ in basal diameter for five Central Valley waterways and statistical significance for comparisons of small stem $(<5-\mathrm{cm}$ diameter) frequency for each of the four dammed rivers to that for the undammed Cosumnes River

\begin{tabular}{lrlll}
\hline & $\begin{array}{l}\text { Total } \\
\text { stems }(n)\end{array}$ & $\begin{array}{l}\text { Stems } \\
<5 \mathrm{~cm}(\%)\end{array}$ & $\begin{array}{l}\text { G-test, \% stems } \\
<5 \mathrm{~cm} \text { : each vs. } \\
\text { Cosumnes }(\mathrm{df}=1)\end{array}$ \\
\cline { 3 - 5 } & & & $G$ & $p$ \\
\hline American River & 789 & 19 & 14.1 & 0.001 \\
Cache Creek & 215 & 19 & 3.88 & 0.05 \\
Cosumnes River & 176 & 21 & - & - \\
Putah Creek & 1076 & 13 & 62.4 & 0.001 \\
Sacramento River & 153 & 5 & 10.5 & 0.01 \\
\hline
\end{tabular}

Black walnut is widely considered invasive on these floodplains, thus it may be invading elderberry habitat that was formerly more open. Studies to elucidate possible impacts of black walnut on blue elderberry are warranted. The effects of associated plant communities on VELB are largely uncertain but potentially important: Talley (2005) and Talley and others (2007) reported a short-term increase in VELB presence but longer-term decrease in blue elderberry survival associated with the introduced, nitrogen fixing tree, Robinia pseudoacacia (black locust).

RE and FPA have been shown to be moderately effective in predicting the distribution of vegetation associations (Vaghti 2003) and riparian tree species (Fremier 2003; Williams 2006) on the Sacramento River. Due to its intolerance of waterlogged soils (Chirman 1994), blue elderberry would be expected on high elevation, typically older floodplain sites. Our vegetation community studies supported this expectation: the FPA and RE patterns can be used to make coarse predictions of where to plant elderberry at the corridorwide scale. Other environmental factors, such as dispersal, canopy cover, and physical conditions, play a large role in recruitment success within reaches of the floodplain (Talley 2005; Fremier and Talley 2008).

\section{Conclusions}

Modern constraints to full process restoration on this large river system place increased importance on horticultural restoration and the maintenance of healthy riparian woodland ecosystems for the recovery of a federally threatened species. We have shown that in natural habitats there are substantial problems caused by invasive species associated with blue elderberry and the lack of small elderberry plants along dammed rivers. Both of these findings indicate that further research is required to ascertain whether

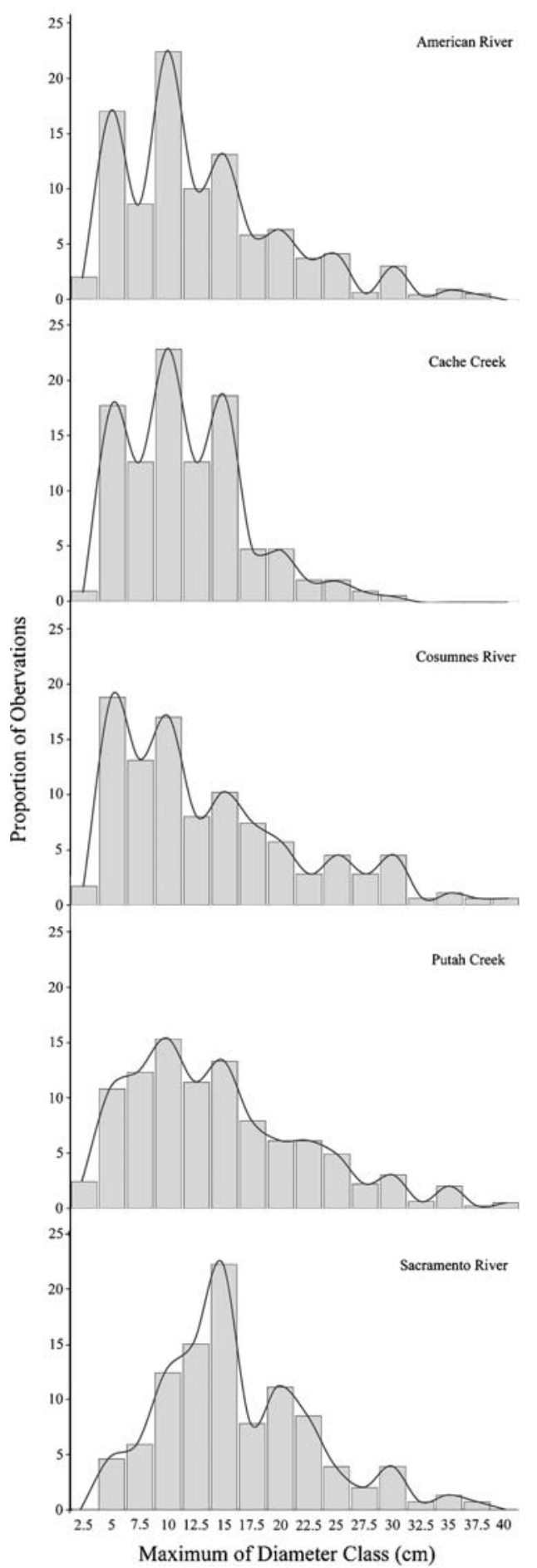

Fig. 5 Distribution of mean blue elderberry stem diameter per 2.5$\mathrm{cm}$ class for five Central Valley waterways. The Cosumnes River is the only river without regulated flow in our study

intervention is necessary to maintain functional and diverse riparian woodlands. Our analyses here were deliberately focused on blue elderberry, but the community associations clearly demonstrate that certain habitat types are infrequent, and that there is a need to monitor the composition 
of riparian woodlands over time, especially in relation to flow regulation.

Acknowledgments Funding for this project was provided by the National Fish and Wildlife Foundation, Sacramento Area Flood Control Agency, Sacramento County Parks, Sacramento County Department of Environmental Review and Assessment, American River Flood Control District, Pacific Gas and Electric, Sacramento Municipal Utility District, Sacramento Regional County Sanitation District, Western Area Power Authority, California Department of Water Resources and Reclamation Board, Federal Highways Administration, the City of Sacramento, and the University of California, Davis. The manuscript was greatly improved by comments from Thomas Griggs, Greg Golet, Karen Holl, and several anonymous reviewers. We thank JayLee Tuil, Chris Alford, Jacob Mann, Alex Young, Sara Wood, Vince King, Angela Calderaro, Tasila Banda, Denise Piechnik, Sarah Ross, Trevor Burwell, and Julie Remp, as well as Bobby Jo Close and the California Conservation Corps mapping crew, for their enthusiastic help with the field studies. We are grateful to Peter Buck (SAFCA), Mary Maret, Guy Kolling, Trevor Burwell (Sac Co. Parks), Richard Marck (SRFCD), Rich Marovich (Putah Creek Streamkeeper), Greg Golet (TNC), Jan Lowry and Melanie Trunan (Cache Creek Conservancy), and David Wright and Joe Silveira (USFWS) for insights as well as access to sites and data.

\section{Reference}

Allen-Wardell G, Bernhardt P, Bitner R, Burquez A, Buchmann S, Cane J, Cox PA, Dalton V, Feinsinger P, Ingram M, Inouye D, Jones CE, Kennedy K, Kevan P, Koopowitz H, Medellin R, Medellin-Morales S, Nabhan GP (1998) The potential consequences of pollinator declines on the conservation of biodiversity and stability of food crop yields. Conservation Biology 12:8-17

Barr CB (1991) The distribution, habitat, and status of the Valley elderberry longhorn beetle Desmocerus californicus dimorphus Fisher (Insecta: Coleoptera: Cerambycidae). U.S. Fish and Wildlife Service, Sacramento, CA

Institute Bay (1998) From the Sierra to the sea: the ecological history of the San Francisco Bay-Delta watershed. Bay Institute, San Francisco

Chirman DB (1994) Nutrient dynamics during establishment of understory woody species in California Central Valley riparian habitats. M.S. thesis. University of California, Davis

CNPS (California Native Plant Society) (2000) Relevé field form and relevé protocol. Revised 04/02/2004. CNPS Vegetation Committee, Sacramento, CA

Dynesius M, Nilsson C (1994) Fragmentation and flow regulation of river systems in the northern third of the World. Science 266:753-762

Federal Register (1980) Listing the Valley elderberry longhorn beetle as a threatened species with critical habitat. Federal Register 45:52803. Friday August 8, 1980. Office of the Federal Register, National Archives and Records Administration

Federal Register (1994) Code of federal regulations: wildlife and fisheries, vol 50, parts 1 to 199. Office of the Federal Register, National Archives and Records Administration

Fremier AK (2003) Floodplain age modeling techniques to analyze channel migration and vegetation patch dynamics on the Sacramento River, California. M.A. thesis. University of California, Davis

Fremier AK, TalleyTS (2008) Scaling riparian conservation efforts with river hydrology: lessons from blue elderberry distributions along four central California rivers. Wetlands (in press)
Gillison AN, Brewer KRW (1985) The use of gradient directed transects or gradsects in natural resource survey. Journal of Environmental Management 20:103-127

Greco SE, Plant RE (2003) Temporal mapping of riparian landscape change on the Sacramento River, miles 196-218, California, USA. Landscape Research 28:405-426

Greco SE, Tuil JL, Parker TM (2003) Land cover mapping of the Sacramento River from 1997 aerial photography: Colusa to Red Bluff (river miles 144-245). Technical report prepared for the California Department of Water Resources, Northern District, Red Bluff. Landscape Analysis and Systems Research Laboratory, Department of Environmental Design, University of California, Davis

Greco SE, Fremier AK, Plant RE, Larsen EW (2007) A tool for tracking floodplain age land surface patterns on a large meandering river with applications for ecological planning and restoration design. Landscape and Urban Planning 81(4):354-373

Greco SE, Girvetz EH, Larsen EW, Mann JP, Tuil JL, Lowney C (2008) Relative elevation topographic surface modeling of a large alluvial river floodplain and applications for the study and management of riparian landscapes. Landscape Research 33:461-486

Hickman JC (ed) (1993) The Jepson manual: higher plants of California. University of California Press, Berkeley

Holyoak M, Koch-Munz M (2008) The effects of site conditions and mitigation practices on success of establishing the Valley elderberry longhorn beetle and its host plant, blue elderberry. Environmental Management 42:444-457

Hubbell JG (1997) Competitive effects of intercropping alfalfa with valley oak and blue elderberry seedlings. Thesis. California State University, Chico

Hughes FMR, Adams WM, Muller E, Nilsson C, Richards KS, Barsoum N, Decamps H, Foussadier R, Girel J, Gilloy H, Hayes A, Johansson M, Lambs L, Pautou G, Peiry JL, Perrow M, Vautier F, Winfield M (2001) The importance of different scale processes for the restoration of floodplain woodlands. Regulated Rivers Resource Management 17:325-345

Hunter JC, Willet KB, McCoy MC, Quinn JF, Keller KE (1999) Prospects for preservation and restoration of riparian forests in the Sacramento Valley, California, USA. Environmental Management 24:65-75

Jones WM (1997) Spatial patterns of woody plant regeneration in two California Central Valley floodplain forests. Thesis. University of Montana

Linsley EG, Chemsak JA (1972) Cerambycidae of North America. Part VI, No. 1. Taxonomy and classification of the subfamily Lepturinae. University of California Publications in Entomology 69:1-138

Neal PR (1998) Pollinator restoration. Trends in Ecology and Evolution 13:132-133

NRC (National Research Council) (2002) Riparian areas: functions and strategies for management. National Academy Press, Washington, DC

Sprenger MD, Smith LM, Taylor JP (2002) Restoration of riparian habitat using experimental flooding. Wetlands 22:49-57

Talley TS (2005) Spatial ecology and conservation of the Valley elderberry longhorn beetle. Ph.D. dissertation. University of California, Davis

Talley TS, Fleishman E, Holyoak M, Murphy D, Ballard A (2007) Rethinking a rare-species conservation strategy in an urbanizing landscape: the case of the Valley elderberry longhorn beetle. Biological Conservation 135:21-32

USFWS (United States Fish and Wildlife Service) (1999) Conservation guidelines for the Valley elderberry longhorn beetle. Department of the Interior, Sacramento, California. Available at: http://sacramento.fws.gov/es/protocol.htm. Accessed 23 October 2008 
Vaghti MG (2003) Riparian vegetation classification in relation to environmental gradients, Sacramento River, California. Thesis. University of California, Davis

Vaghti MG, Greco SE (2007) Riparian vegetation of the Great Valley. In: Barbour M, Keeler-Wolf T, Schoenherr A (eds) Terrestrial vegetation of California, 3rd edn. University of California Press, Berkeley

Williams AM (2006) Modeling the spatial distributions of riparian plant species on the Sacramento River, California, with conservation applications. Thesis. University of California, Davis 